Resenhas 



\title{
SILVA, Sidney de Souza (org.). Línguas em Contato: Cenários de Bilinguismo no Brasil. Coleção Linguagem e Sociedade v.2. Campinas/SP: Pontes Editores, 2011.
}

\author{
Adriana Dalla Vecchia \\ Faculdade Campo Real \\ Letícia Fraga \\ Universidade Estadual de Ponta Grossa
}

O livro acima citado faz parte de um rol bastante recente de obras que abordam o tema bilinguismo numa perspectiva contemporânea, a partir da qual se considera o uso de línguas diferentes em um mesmo contexto, servindo cada uma delas para práticas linguísticas distintas. Sidney de Souza Silva, que é estudioso da temática cujo enfoque recai sobre os contextos de imigração e outros grupos étnicos, fez um primoroso trabalho ao reunir pesquisadores que pensam o tema por esse mesmo viés, mostrando as verdadeiras práticas bilíngues e multilíngues - admitindo que cada língua também se realiza em diversas variedades, sendo estas, algumas vezes, incompreensíveis entre si - descortinando assim um Brasil plurilíngue.

Segundo o organizador, seu objetivo com a coletânea é "dar visibilidade aos estudos linguísticos voltados para o fenômeno de línguas em contato no território brasileiro" (p. 15). Esse alvo nos mostra que as preocupações de Silva giram em torno de demonstrar a existência de muito mais línguas em contato dentro do país do que poderíamos julgar, o que contribui para que a imagem do Brasil monolíngue se desmantele de vez. Não é de hoje que linguistas têm se dedicado a descrever um cenário linguístico brasileiro mais condizente com a realidade, no entanto nunca antes houve tantos pesquisadores dispostos a saírem da torre de marfim a fim de verem o uso das línguas. Assim, ter uma obra que reúna alguns deles pode também contribuir para o fortalecimento dessa área tão nova.

A discussão ganha peso pela organização dada ao livro. Silva agrupa os treze capítulos em três partes distintas, cada uma reunindo textos relativos a pesquisas cujos objetos de estudos são próximos: a primeira congrega os Estudos Linguísticos em Contextos de Comunidades Indígenas; a segunda seção ocupa-se dos Estudos Linguísticos em Contextos de Imigração e a última evidencia os Estudos Linguísticos em Regiões de Fronteira. Antecedendo esses textos, apresenta-se uma introdução escrita por Clara Dornelles que questiona o monolinguismo atribuído ao Brasil, demonstrando que essa visão tem sido "desafiada pela diversidade que se 
faz cada vez mais visível no país” (SILVA, p. 16), conforme reflete Silva na apresentação da obra.

Na primeira parte do livro, encontramos capítulos de Dulce do Carmo Franceschini, Ana Suely Arruda Câmara Cabral e Silvia Lucia Bigonjal Braggio. Cada uma dessas estudiosas realiza suas pesquisas em comunidades indígenas distintas, o que nos proporciona conhecer essas realidades antes apagadas e também observar o que há de comum entre os usos e reflexões linguísticas em cada âmbito. Respectivamente, as autoras investigam os usos linguísticos feitos pelos Mawé, os Zo’é e os Xerente. Esses três povos passaram, em níveis diferentes, por um processo de perda da sua língua materna em consequência do contato inevitável com a língua portuguesa. Além disso, os três povos sentiram a necessidade de realizar políticas linguísticas de resistência para manter não somente sua língua materna bem como sua cultura.

As discussões dessas autoras trazem à tona, cada uma a seu modo, uma distinção bastante importante quando se trata de línguas em contato. De acordo com Franceschini, dizer que há contato entre línguas pode camuflar a realidade conflituosa que se instaura a partir do momento em que duas línguas convivem em um mesmo ambiente. Para a autora, "[a] s 'relações' entre as línguas indígenas brasileiras e o português desde o período colonial até os dias de hoje podem ser caracterizadas muito mais como situações de conflito do que situações de contato de línguas” (FRANCESCHINI, p. 42). Isso se explica pelo fato de sempre haver "hierarquização das línguas em contato, a qual refletiria a hierarquização desta sociedade e, portanto, a essas línguas seriam atribuídos diferentes valores sociais" (FRANCESCHINI, p. 43).

Mello, em prefácio à obra de Silva, concorda com a visão apresentada e discutida pelas autoras. Segundo ela, "[o] que costumamos chamar de contato entre línguas é na verdade contato entre falantes”, o qual está "longe de ser neutro, [pois] esse contato é sempre marcado pelas atitudes, sentimentos e julgamentos de valor que os falantes desenvolvem entre si e em relação às línguas que falam” (MELLO, p. 9).

Nesse sentido, podemos dizer que nenhum contato é neutro e é pertinente a reformulação do conceito de diglossia feito pela autora a partir das discussões de Cichon (1997), segundo o qual "a diglossia neutra seria uma impressão, não uma realidade” (CICHON, 1997 apud FRANCESCHINI, p. 45). A partir do novo conceito, considera-se que qualquer situação de contato entre línguas é conflituosa, jamais harmoniosa. Isso se comprova pelas considerações de Cabral e Braggio, que demonstram situações em que a língua majoritária, a portuguesa, ganha espaço nas comunidades estudadas, ocupando inclusive o espaço antes destinado à língua materna. Em termos de prestígio, o português não oferece chance de as línguas maternas se imporem, pois as situações em que o seu uso é imprescindível são 
inúmeras e até incontáveis se relacionadas aos usos necessários da língua indígena.

Em todos os textos, há indicativas de que políticas linguísticas de resistência já implantadas ou para serem implantadas podem resolver a situação de deslocamento das línguas indígenas. A respeito disso, é importante ressaltar que se tais políticas não partirem das necessidades das comunidades, podem não surtir o efeito pretendido e ainda enfastiarem os usuários das línguas indígenas. Afinal, deve-se lembrar que historicamente o Brasil implantou, quase exclusivamente, políticas linguísticas em prol do monolinguismo em português com o intuito de viabilizar uma imagem de Estado-Nação consolidado, igualando uma língua a uma nação. Isso não propiciou a continuidade das línguas indígenas, pelo contrário, fê-las assumirem a posição de línguas minorizadas. Muitas comunidades deixaram de falar suas línguas maternas e passaram a usar apenas o português, nesse caso, para algumas delas pode não ser tão interessante trabalhar para a implantação de uma política que revitalize a língua materna. Assim, é imprescindível que se considerem os desejos e necessidades das comunidades a fim de se pensarem políticas linguísticas destinadas para tais grupos.

Na segunda parte do livro, Silva traz os textos de Heloísa Augusta Brito de Mello, Mabel Petterson Prudente e Carmen Maria Faggion que escreve em parceria com Terciane Ângela Luchese. Além delas, contribuem com as discussões Neiva Mara Zanin Garcia, Letícia Fraga e o próprio Sidney de Souza Silva. Os pesquisadores ocupam-se em discutir questões relativas ao contato entre línguas proporcionado pela imigração, ou seja, situações de bilinguismo geradas no interior de grupos linguísticos cuja língua materna é alóctone. Respectivamente, os autores tratam de colônias de imigração inglesa, árabe, italiana, ucraniana, holandesa e alemã em diferentes regiões do Brasil, desde Goiás até o Rio Grande do Sul, passando por Minas Gerais e Paraná.

A questão de o contato linguístico observado pelos pesquisadores não ser neutro e harmonioso também permeia esses textos. Conforme mencionado acima, a convivência entre línguas de imigração também é uma situação conflituosa em sua maioria. Silva, no capítulo de sua autoria, faz referência a essa questão relembrando Cavalcanti (1999), segundo a qual, parafraseada pelo articulista, "não existe contato sem conflito, visto que há sempre uma relação assimétrica de poder, em maior ou menor grau, entre os grupos envolvidos” (SILVA, p. 121). O autor vai além, fazendo uma analogia interessante: "[o] contato entre línguas é visto também como línguas em competição, pois nas situações de hegemonia linguística, uma língua se torna dominante, enquanto a outra passa a ser considerada como inferior, ou de menor prestígio" (SILVA, p. 121).

Dos casos analisados nessa seção do livro, exceto da pesquisa realizada por Mello, identificaram a língua portuguesa como majoritária e de 
maior prestígio nas comunidades. A partir desse status, o português, por um processo de deslocamento, paulatinamente tem substituído as línguas alóctones. Nos casos expostos por Silva e por Faggion e Luchese, houve deslocamento total das línguas alemã e italiana, tanto uma quanto a outra não são mais transmitidas em família ou ensinadas na escola da comunidade, restaram apenas alguns traços característicos.

No tocante à pesquisa de Mello, a língua majoritária deixa de ser o português, pois este perde prestígio frente ao inglês falado pela comunidade rural de origem norte-americana situada no sudoeste de Goiás. Segundo a autora, o inglês é uma "língua de prestígio internacional que apesar de numericamente minoritária em certos contextos [como o pesquisado por elas] nem sempre se encontra na condição de minorizada, visto que no Brasil saber falar inglês é um bem cultural bastante apreciado" (MELLO, p. 142). Enquanto as demais comunidades que nos foram apresentadas nesta parte do livro lutam para manter se não a língua em toda a sua estrutura ao menos os traços característicos, o grupo linguístico norte-americano é, conforme Mello informa, admirado pela população brasileira pela sua organização, religiosidade, potencial de trabalho e conduta íntegra.

No caso específico analisado por Mello, o conflito, para a autora, “é minimizado em razão do prestígio que a língua inglesa tem na sociedade brasileira e da situação econômica privilegiada que gozam os membros dessa comunidade na região" (MELLO, p. 157). Totalmente oposta é a situação dos falantes da língua árabe, tratada por Prudente, os quais utilizam somente a língua em domínios privados, de preferência, quando todos falam tal língua ou a tem como única língua. Em caso contrário, ou seja, em domínios públicos, reina a língua portuguesa como soberana. O fato de a língua árabe não ter prestígio internacional pode motivar o uso apenas em domínios privados. É o caso dos falantes de italiano e alemão que perderam prestígio na época pós-guerra e durante o Estado Novo, conforme explicam Silva, Faggion e Luchese, por serem as línguas dos inimigos de guerra do Brasil e dos Aliados.

Essas ocorrências nos levam a refletir sobre outro aspecto que perpassa todos os textos desta seção: línguas distintas em contato servem cada uma para domínios diferentes e cada vez mais o português tem entrado em domínios antes apenas ocupados por línguas alóctones, causando de modo lento um deslocamento. Parafraseando Fishman (1968), Mello observa que "domínio é uma situação particular na qual ocorre uma determinada interação social”, assim temos a interação entre pessoas da mesma família pertencente ao domínio familiar e a interação no ambiente profissional inserido no domínio profissional qualquer que seja a área. Para Mello,

cada um desses domínios [escola, igreja, família, trabalho, rua, vizinhança] pode exigir uma língua ou mais, dependendo do local onde ocorre a interação, dos participantes da interação, da formalidade ou informalidade da 
situação e da função da interação. Assim a noção de domínios linguísticos não se restringe ao local propriamente dito, mas à situação como um todo e está também atrelada às expectativas de uso da(s) língua(s) num contexto específico. (MELLO, p. 145, ênfase conferida).

Nesse caso, em cada situação de interação, no caso de comunidades bilíngues, utiliza-se uma ou outra língua. Em geral, pela exposição nos textos desta seção, ao domínio público é reservada a língua portuguesa e ao domínio privado reserva-se a língua alóctone. Não entra nesse caso a comunidade explorada por Mello, na qual há uma inversão: a língua alóctone, o inglês, está presente em todos os domínios dentro da colônia de imigração, servindo o português para os contatos fora desse local.

A terceira parte do livro abriga textos resultantes de pesquisas empreendidas em contextos plurilíngues de fronteira. Marilucia Marques do Espírito Santo reflete sobre a função da escola no município de Oiapoque, fronteira com Saint-Georges, Guiana Francesa. Os demais textos apresentam a situação de contato linguístico em trechos da fronteira oeste do Brasil: Clarice Von Borstel aborda a região de Guaíra(Paraná) e María Josefina Israel Semino em colaboração com Patrícia Mussi Escobar demonstram suas investigações na fronteira Sul Brasil e Uruguai.

As autoras, de forma tangencial, abordam também, cada uma dentro do contexto pesquisado e seguindo sua linha teórica, a situação conflituosa gerada pelo contato entre falantes de línguas cujo status é diferente, em que uma é mais valorizada que outra. No entanto, o que é foco das três pesquisas é o fenômeno code-switching bastante comum em comunidades plurilíngues. Tal ocorrência linguística é explicada por Borstel como sendo uma hibridização das línguas em contato que pode se dar de diferentes formas: tags switching (uso de expressões retóricas e idiomáticas da outra língua); intersentential switching (quando o uso de frases isoladas de línguas distintas é feito para a expressão em uma determinada língua); e o intra-sentential switching (ocorre "no meio de frases, ou em partes de frases, e, com isso, exige uma maior competência do falante bilíngue [ou multilíngue]” (BORSTEL, p. 318).

Evidenciar tais situações é de extrema importância para se conhecer o funcionamento da expressão de sujeitos bilíngues ou multilíngue, os quais têm à sua disposição uma gama maior de línguas que lhes auxilia na construção do significado dos fatos. Em oposição ao monolíngue, que tem apenas uma língua para atribuir significados e compreender os fatos, os bilíngues e os multilíngues podem lançar mão de mais sistemas para compreensão e expressão do que está à sua volta. Assim, podemos supor que ser monolíngue passa a ser limitado no que se refere à significação e ser bilíngue ou multilíngue lhe dá mais possibilidades de interação. Tal visão se opõe à visão tradicional de bilinguismo, segundo a qual ser bilíngue 
impediria que o sujeito se comunicasse de modo perfeito em qualquer uma das línguas, tendo em vista que o code-switching é um processo inevitável.

É importante salientar a respeito desses textos que o contato das línguas nas fronteiras também acontece em função da disputa territorial e das relações sociais e econômicas mantidas entre os municípios de países diferentes, mas que são irmãos pelo território. Conforme explica Marilucia do Espírito Santo a respeito de seu locus de pesquisa, Oiapoque, "as necessidades econômicas do município e a proximidade com a Guiana Francesa potencializam as motivações dessa língua face às oportunidades sociais e econômicas que o aprendizado da mesma representa na região" (ESPIRITO SANTO, p. 303).

Nesse caso, há atitudes positivas dos habitantes da região em relação à língua francesa, sendo a presença da língua francesa no lado brasileiro bastante intensa não somente nas interações, mas também nas placas de bem-vindos, nas indicativas dos estabelecimentos comerciais e nas oficiais do governo do Amapá, além de estar presente nas inscrições dos monumentos. Em contraposição, no lado guianense, a presença do português é praticamente nula. Ou seja, o francês é a língua de prestígio na região e o português, apesar de ser a majoritária, não angaria tanto prestígio, pois, na região de concentração da pesquisa, a força econômica é maior do lado guianense. Do mesmo modo, Semino e Escobar demonstram ocorrer na fronteira em que espanhol e português estão em contato; nessa relação, porém, a força maior é do português, tendo em vista sua melhor situação econômica e social e o prestígio internacional do Brasil em contraposição ao contexto do Uruguai.

Outra contribuição dessas discussões, sobretudo a de Marilucia do Espírito Santo, é trazer o questionamento do papel da escola tanto para a consolidação de preconceitos e visões sociais a respeito das línguas como também para o estabelecimento de políticas linguísticas. Segundo a autora, "[a] escola [...] é o ambiente comunicativo que mais propicia a eclosão do bilinguismo social” na região (ESPÍRITO SANTO, p. 303). Afinal de contas, encoraja o uso da língua francesa no ambiente mesmo havendo poucos investimentos para o ensino dessa língua. Nesse sentido, podemos dizer que a comunidade local, sentindo a necessidade de usar o francês, inseriu na escola o seu ensino; mas essa escolha linguística proveniente da realidade in vivo ainda não foi endossada pelo Estado, como explica a autora. Para ela, o ideal seria que o Estado interviesse e garantisse o ensino de francês na escola pública do mesmo modo que ocorreu na fronteira sul, onde há escolas bilíngues de fronteira que procuram atender as necessidades e desejos das comunidades locais.

Por fim, Silva constrói junto a Mello um posfácio ao livro no qual reiteram sua intenção de trazer à tona situações linguísticas que demonstram ser o Brasil um país multilíngue. Além disso, mostra, a partir das pesquisas 
apresentadas, a necessidade de se estudar a língua em sua interface com a sociedade "naquilo que ela tem de mais encantador, que é a diversidade - a diversidade de falares, a diversidade de sotaques, de etnias, de culturas" (SILVA e MELLO, p. 351).

Tendo essa configuração e o propósito já exposto e reiterado, consideramos um livro capaz não somente de esclarecer sobre os contextos descortinados por cada um dos pesquisadores, mas também de despertar novos estudiosos para, como dizem Silva e Mello no posfácio, iluminarem novos cenários que contribuam para a reflexão acerca do estabelecimento e da manutenção de políticas linguísticas locais que atendam às demandas de cada comunidade. Assim, a contribuição é no sentido de demonstrar que o Brasil é um país plurilíngue e não monolíngue, imagem esta que tantas políticas linguísticas repressivas tentaram impor.

Recomenda-se a leitura deste livro para todos os acadêmicos da área de Letras para que construam sua formação a partir de um entendimento de língua menos fechado, abrangendo às situações reais de uso. Ainda é pertinente a leitura por parte daqueles pesquisadores que se interessam pelo contato com a realidade e não conseguem permanecer na torre de marfim. 